\title{
Topoisomerase Il $\alpha$ mRNA and protein expression in ovarian carcinoma: correlation with clinicopathological factors and prognosis
}

\author{
Areeg Faggad ${ }^{1,5}$, Silvia Darb-Esfahani ${ }^{1,5}$, Ralph Wirtz ${ }^{2}$, Bruno Sinn ${ }^{1}$, Jalid Sehouli ${ }^{3}$, \\ Dominique Könsgen ${ }^{3}$, Hermann Lage ${ }^{1}$, Wilko Weichert ${ }^{1}$, Aurelia Noske ${ }^{1}$, Jan Budczies ${ }^{1}$, \\ Berit M Müller ${ }^{1}$, Ann-Christin Buckendahl ${ }^{1}$, Annika Röske ${ }^{1}$, Nasr Eldin Elwali ${ }^{4}$, Manfred \\ Dietel $^{1}$ and Carsten Denkert ${ }^{1}$ \\ ${ }^{1}$ Institute of Pathology, Charité University Hospital, Berlin, Germany; ${ }^{2}$ Siemens Healthcare Diagnostics, \\ Köln, Germany; ${ }^{3}$ Department of Gynecology and Obstetrics, Charité University Hospital, Berlin, Germany \\ and ${ }^{4}$ National Cancer Institute, University of Gezira, Wad Medani, Sudan
}

\begin{abstract}
Topoisomerase Il $\alpha$ (Top Il $\alpha$ ) is a nuclear enzyme that plays a central role in DNA metabolism, and is a molecular target for a variety of chemotherapeutic agents. Top Il $\alpha$ has recently gained attention as a biomarker for therapy response and patient survival. In this study, we attempted to assess the feasibility of measuring Top Il $\alpha$ gene expression in RNA, isolated from archival formalin-fixed paraffin-embedded tissue specimens, which are used routinely in pathology laboratories. We have employed a new technique on the basis of magnetic particles' separation and purification of nucleic acids, and evaluated both protein and mRNA expressions from the same routinely processed tissue blocks. We investigated the expression of Top Il $\alpha$ mRNA and protein by real-time reverse transcription polymerase chain reaction and immunohistochemistry, in a cohort of 133 primary ovarian carcinomas, and evaluated the association between Top Il $\alpha$ expression and clincopathological variables as well as patient outcome. Elevated Top Il $\alpha$ mRNA expression was observed in high-grade tumors $(P=0.003)$ and advanced stage disease $(P=\mathbf{0 . 0 1 1})$. In univariate Kaplan-Meier analysis, patients with higher expression of Top Il $\alpha$ nuclear protein had a significantly decreased overall survival $(P=0.045)$. Interestingly, we detected cytoplasmic protein expression of Top Il $\alpha$ in a subset of samples. Cytoplasmic expression of Top Il $\alpha$ was associated with the expression of chromosomal region maintenance/exportin 1 (CRM1)-a nuclear export protein $(P=0.008)$. Our study suggests that Top Il $\alpha$ overexpression is involved in the progression of ovarian cancer in a subset of the patients. Our results encourage the further evaluation of the prognostic and predictive values of Top Il $\alpha$ expression in ovarian carcinoma, which might help to assess the patients' risk profile, and the planning of an individualized therapy.

Modern Pathology (2009) 22, 579-588; doi:10.1038/modpathol.2009.14; published online 6 March 2009
\end{abstract}

Keywords: ovarian carcinoma; prognosis; topoisomerase II $\alpha$; Top II $\alpha$

Ovarian cancer is the major cause of gynecologic cancer mortality. In 2008, it is estimated that about 21650 women will be diagnosed with ovarian carcinoma in the United States; and about 15520 women will die of the disease, ranking as the eighth most frequent malignancy and fifth leading cause of female cancer deaths. The 5-year survival rate is only $45 \% .^{1}$

Correspondence: Professor Dr C Denkert, Institute of Pathology, Charité Universitätsmedizin Berlin, Campus Mitte, Charitéplatz 1, Berlin D-10117, Germany.

E-mail: carsten.denkert@charite.de

${ }^{5}$ These authors contributed equally to this work.

Received 13 June 2008; accepted 8 December 2008; published online 6 March 2009
Owing to its location and the lack of early clinical symptoms and non-availability of effective screening tests, ovarian cancer is usually diagnosed at an advanced stage. Primary radical surgery with the aim of maximal cytoreduction followed by adjuvant chemotherapy with carboplatin and paclitaxel is the cornerstone in the clinical management of ovarian cancer. Although such therapeutic intervention results in a disease remission, most patients will relapse and die because of tumor progression. ${ }^{2}$

Prognosis and selection of therapy is influenced mainly by disease stage, in addition to patient age, histological type and grade of the tumor. Identification of novel molecular targets relevant to diagnosis, prognosis and prediction of response to therapy is essential. The new therapeutic strategies focus on 
the combination of molecular targeted therapies with cytotoxic agents, which might lead to an improvement in treatment response and patient outcome.

Topoisomerase II $\alpha$ (Top II $\alpha$ ) plays a central role in DNA metabolism, including DNA replication, transcription, DNA recombination, chromosome condensation and organization of chromosome structure,$^{3-5}$ and is a marker of cell proliferation. ${ }^{6-8}$ Top II $\alpha$ is a molecular target for a variety of antineoplastic agents, including anthracyclines (eg, pegylated doxorubicin, daunorubicin), epipodophyllotoxins (eg, etoposide (VP16)), teniposide (VM-26), aminocridines (mAMSA), anthracenediones (eg, mitoxantrone) and actinomycin D. They are referred as topoisomerase II inhibitors. These agents bind the DNA-Top II $\alpha$ complex and inhibit the religation of DNA. As a consequence, DNA breaks accumulate in the cell and trigger cell death. ${ }^{9-12}$ Topoisomerase II $\alpha$ gene expression has been suggested to predict tumor sensitivity to chemotherapy. ${ }^{8,14}$

Top II $\alpha$ expression, genetic alteration and enzyme activity have been studied in malignancies of different types. ${ }^{15-20}$ However, earlier studies investigated Top II $\alpha$ mRNA expression using frozen tissues as it had been expected that formalin fixation and paraffin embedding result in fragmentation of nucleic acids and chemical modification by protein-protein and protein-nucleic acid cross-links, making RNA extracted from such processed tissues unsuitable for molecular analysis techniques. Nevertheless, recent studies have proved the reliable gene expression measurement of RNA isolated from formalin-fixed paraffin-embedded (FFPE) tissues. $^{21,22}$ As the detection of biomarkers on the mRNA level in FFPE tissue is becoming increasingly important in pathological diagnosis, we have evaluated a novel technique for RNA extraction from FFPE tissue, which is based on magnetic particles for separation and purification of nucleic acids. We attempted to assess the feasibility of measuring Top II $\alpha$ gene expression in RNA isolated from archival FFPE tissue specimens, which are used routinely in pathology laboratories.

The cellular functions of topoisomerase II $\alpha$ as a marker of proliferation, a molecular target for chemotherapeutic drugs and a predictive marker for response to topoisomerase II inhibitors raise the hypothesis that Top II $\alpha$ might be involved in the development and progression of ovarian carcinoma. We further hypothesized that the nuclear export protein chromosomal region maintenance/exportin 1 (CRM1), which mediates nuclear export of proteins and mRNAs, ${ }^{23}$ is involved in the regulation of the subcellular localization of Top II $\alpha$.

In this study, we investigated these hypotheses in a large cohort of primary ovarian carcinomas. The aim of this study was to investigate topoisomerase II $\alpha$ expression at RNA and protein level, and to evaluate the relationship between Top II $\alpha$ expression and clincopathological factors as well as outcome variables in patients with invasive ovarian cancer on the one hand and CRM1 expression on the other. We focussed on the hypothesis that a correlation of Top II $\alpha$ expression with the tumor proliferation can be detected at mRNA level in an FFPE tissue-based approach. We carried out measurement of mRNA expression by quantitative real-time reverse transcription polymerase chain reaction (qRT-PCR) using RNA isolated from FFPE tissues in addition to immunohistochemistry staining to evaluate protein expression.

\section{Materials and methods}

\section{Study Population}

The study group included 133 patients who underwent surgery for primary ovarian cancer at the Department of Gynecology and Obstetrics of the Charité University Hospital, Berlin, Germany between 1991 and 2004. Specimens of all patients were examined and diagnosed at the Institute of Pathology, Charité University Hospital, Berlin, Germany. Selection of cases was on the basis of availability of tumor tissue together with follow-up data. Histology and grade were re-evaluated by an experienced gynecopathologist (CD). Hematoxylin and eosin (H\&E)-stained sections were cut from paraffin-embedded blocks and used for histopathological evaluation; grading of tumors was assessed using Silverberg grading system; ${ }^{24}$ and staging of tumors was carried out according to the International Federation of Gynecology and Obstetrics (FIGO) staging system.

Patients underwent primary surgery with the goal of maximal tumor resection followed by standard combination chemotherapy with carboplatin and paclitaxel. None of the patients had received chemotherapy before surgery and collection of the tumor specimens. The patient characteristics are presented in Table 1. Data regarding postoperative chemotherapy were available for 121 patients (91\%); of these patients, $112(92.6 \%)$ received a platinumbased chemotherapy, $3(2.5 \%)$ received other regimens and $6(5.0 \%)$-who were FIGO stage I-did not receive any chemotherapy.

Data on intraoperative residual tumor were available for 93 patients; of these patients, 81 (87.0\%) had a postoperative residual tumor of less than $2 \mathrm{~cm}$ (Table 1).

\section{Immunohistochemical Staining and Evaluation}

Immunohistochemical staining was performed on tissue microarrays (TMAs), which were constructed by selection of representative tumor areas that were marked on the routine H\&E-stained histological sections. For each case, four tissue cores $(1.5 \mathrm{~mm}$ diameter) from different tumor areas of the sample tissue blocks were punched using a tissue 
Table 1 Characteristics of ovarian carcinoma patients

\begin{tabular}{|c|c|c|}
\hline Characteristic & $\begin{array}{l}\text { Protein expression } \\
\text { (all cases, } \mathrm{n}=133 \\
\qquad \% \text { (\%) }\end{array}$ & $\begin{array}{c}\text { RNA expressior } \\
\text { (all cases, } \mathrm{n}=10 \\
(\%)\end{array}$ \\
\hline \multicolumn{3}{|l|}{ Histological type } \\
\hline Serous & $82(61.7 \%)$ & $67(67.0 \%)$ \\
\hline Non-serous & $37(27.8 \%)$ & $24(24.0 \%)$ \\
\hline Undifferentiated & $14(10.5 \%)$ & $9(9.0 \%)$ \\
\hline \multicolumn{3}{|l|}{ FIGO stage } \\
\hline I & $26(19.5 \%)$ & $17(17.0 \%)$ \\
\hline II & $12(9.0 \%)$ & $9(9.0 \%)$ \\
\hline III & $86(64.7 \%)$ & $68(68.0 \%)$ \\
\hline IV & $9(6.8 \%)$ & $6(6.0 \%)$ \\
\hline \multicolumn{3}{|l|}{$p T$} \\
\hline pT1 & $29(21.8 \%)$ & $19(19.0 \%)$ \\
\hline pT2 & $15(11.3 \%)$ & $12(12.0 \%)$ \\
\hline pT3 & $89(66.9 \%)$ & $69(69.0 \%)$ \\
\hline$p N$ & $(n=106)$ & $(n=80)$ \\
\hline pNo & $51(48.1 \%)$ & $40(50.0 \%)$ \\
\hline pN1 & $55(51.9 \%)$ & $40(50.0 \%)$ \\
\hline \multicolumn{3}{|l|}{$p M$} \\
\hline pMX & $124(93.2 \%)$ & $94(94.0 \%)$ \\
\hline pM1 & $9(6.8 \%)$ & $6(6.0 \%)$ \\
\hline \multicolumn{3}{|c|}{ Histological grade (Silverberg) } \\
\hline G1 & $22(16.5 \%)$ & $15(15.0 \%)$ \\
\hline G2 & $57(42.9 \%)$ & $43(43.0 \%)$ \\
\hline G3 & $54(40.6 \%)$ & $42(42.0 \%)$ \\
\hline \multicolumn{3}{|l|}{ Age at surgery (years) } \\
\hline$\leq 60$ & $77(57.9 \%)$ & $56(56.0 \%)$ \\
\hline$>60$ & $56(42.1 \%)$ & $44(44.0 \%)$ \\
\hline Intraoperative residual & $(n=93)$ & $(n=72)$ \\
\hline \multicolumn{3}{|l|}{ tumor } \\
\hline Residual tumor $\leq 2 \mathrm{~cm}$ & $81(87.1 \%)$ & $63(87.5 \%)$ \\
\hline Residual tumor $>2 \mathrm{~cm}$ & $12(12.9 \%)$ & $9(12.5 \%)$ \\
\hline Chemotherapy & $(n=121)$ & $(n=90)$ \\
\hline Platinum-based & $112(92.6 \%)$ & $86(86.0 \%)$ \\
\hline Non-platinum & $3(2.4 \%)$ & $1(1.0 \%)$ \\
\hline No chemotherapy & $6(5.0 \%)$ & $3(3.0 \%)$ \\
\hline
\end{tabular}

FIGO, International Federation of Gynecology and Obstetrics; pM, metastasis stage; $\mathrm{pN}$, node stage; $\mathrm{pT}$, tumor stage.

micro-arrayer (Beecher Instruments; Woodland, CA, USA), and embedded into a new paraffin array block. Immunohistochemical staining was performed according to standard procedures. Briefly, slides were deparaffinized in xylene, and gradually rehydrated in graded solutions of ethanol. For antigen retrieval, slides were boiled in $0.01 \mathrm{M}$ citrate buffer (pH 6.0) in a pressure cooker for $5 \mathrm{~min}$, and they were incubated in protein block reagent (Dako, Glostrup, Denmark) for $10 \mathrm{~min}$ at room temperature, and subsequently incubated overnight at $4^{\circ} \mathrm{C}$ with a polyclonal rabbit antibody directed against human topoisomerase II $\alpha$ (Bio-trend chemicals, Cologne, Germany), diluted 1:400 in an antibody diluent solution (Zytomed, Berlin, Germany). This was followed by incubation with a biotinylated anti-Ig universal secondary antibody and the biotin-strep- tavidin-amplified detection system multilink-alkaline phosphatase (Biogenex, San Ramon, CA, USA). After the development of color with fast-red chromogen system (Sigma, Steinheim, Germany), the slides were counterstained with Mayer's hematoxylin, and cover slips were applied with Aquatex (Merck, Darmstadt, Germany).

Topoisomerase II $\alpha$ immunostaining in tumor cells was evaluated without prior knowledge of clinicopathological parameters and patient outcome. Two staining patterns of Top II $\alpha$ were observed (nuclear and cytoplasmic); they were assessed and scored independently. Top II $\alpha$ immunoreactivity was evaluated according to the percentage of positive cells and the intensity of staining. The percentage of positive cells was scored as $0(0 \%) ; 1(1-10 \%) ; 2$ (11-50\%); 3 (51-80\%); and 4 (> 80\%). The staining intensity was scored as 0 (negative), 1 (weak), 2 (moderate) and 3 (strong). For the immunoreactive score (IRS), the percentage of positive cells and staining intensity was multiplied, resulting in a value between 0 and 12 . To distinguish cases with a weak or a strong expression of Top II $\alpha$ in tumor tissue, we combined cases with an IRS of $0-3$ to one group with negative to weak Top II $\alpha$ expression (Top II $\alpha$-low expression), whereas cases with an IRS of 4-12 were combined into Top II $\alpha$-high-expression group.

Immunohistochemical staining and evaluation of CRM1 were performed according to the standard procedures as described previously. ${ }^{25}$

\section{RNA Extraction}

A total of 100 cases, which were a subset of the total cohort were examined for Top II $\alpha$ mRNA expression in FFPE tissue, as well. The clinicopathological data for this subgroup of patients are shown in Table 1, and is generally comparable to the whole cohort.

All samples included in the study contained at least $60 \%$ tumor tissue as evaluated by H\&E staining. A $10-\mu \mathrm{m}$ thick section was cut from each paraffin block and set in a 1.5-ml Eppendorf tube. RNA was extracted using magnetic bead-based technique developed by Siemens Healthcare Diagnostics Research (Köln, Germany) according to a standard protocol provided by the manufacturer. In brief, the FFPE section was deparaffinized in xylol and rehydrated in graded solutions of ethanol. The pellet was let to dry at room temperature for $10 \mathrm{~min}$, lysed in lysis buffer and sodium dodecyl sulfate (SDS) for $5 \mathrm{~min}$ at $95^{\circ} \mathrm{C}$; then proteinase $\mathrm{K}$ was added and 2 -h incubation at $56^{\circ} \mathrm{C}$ with shaking was carried out. A binding buffer and the magnetic beads were added, and nucleic acids were allowed to bind to the beads for $15 \mathrm{~min}$ at room temperature aided by shaking. On a magnetic rack, the supernatant was removed and beads were washed several times with washing buffers. After the addition of elution buffer and incubation for $10 \mathrm{~min}$ at $70^{\circ} \mathrm{C}$ with strong 
shaking, the supernatant was transferred to a new tube without touching the beads on the magnetic rack. This was followed by DNAse I treatment for $30 \mathrm{~min}$ at $37^{\circ} \mathrm{C}$, and subsequently the inactivation of DNAse I, using TURBO DNA-free kit according to the procedure provided by the manufacturer (Ambion, Austin, TX, USA); after a short centrifugation, the supernatant was removed carefully, kept at $-80^{\circ} \mathrm{C}$ and used for real-time qRT-PCR).

\section{Real-Time qRT-PCR}

Topoisomerase II $\alpha$ mRNA expression in a total of 100 FFPE samples was evaluated by real-time qRTPCR that was performed using intron-spanning TaqMan primers and fluorogenic probes for Top II $\alpha$ and RPL37A genes (Siemens Healthcare Diagnostics). All the reactions were carried out on a LightCycler instrument (Roche Diagnostics, Mannheim, Germany) using Superscript III Platinum One-Step qRT-PCR System (Invitrogen, Karlsruhe, Germany) in a $20-\mu$ l reaction volume. The following conditions were employed: $30 \mathrm{~min}$ at $50{ }^{\circ} \mathrm{C}$ for reverse transcription, $2 \mathrm{~min}$ at $95^{\circ} \mathrm{C}$ for Taq activation followed by 40 cycles of $95^{\circ} \mathrm{C}$ for $15 \mathrm{~s}$ and $60^{\circ} \mathrm{C}$ for $30 \mathrm{~s}$ for amplification. No-template controls were included in every reaction run.

The comparative threshold cycle $\left(C_{\mathrm{t}}\right)$ method was used for the calculation of amplification fold as specified by the manufacturer. RPL37A was employed as a housekeeping gene at a cycle threshold $\left(C_{\mathrm{t}}\right)$ of 25. Top II $\alpha$ and RPL37A mRNA quantities were analyzed in duplicate, and mean $C_{\mathrm{t}}$ levels were used for data analyses. A normalized score $\left(40-\Delta C_{\mathrm{t}}\right)$ that has a proportional correlation to relative RNA transcriptional level was calculated. In cases where Top II $\alpha$ mRNA expression could not be measured despite adequate positive controls, the $C_{\mathrm{t}}$ value was estimated as 40 , resulting in a normalized score of zero. Using $\left(2^{40-\Delta C_{t}}\right)$ virtual copy numbers were calculated. To separate cases with low and high expressions, the median of virtual copy numbers was used as the cutoff point for Top II $\alpha$ mRNA expression.

\section{Statistical Evaluation}

The statistical significance of the association between Top II $\alpha$ expression and clinicopathological parameters was assessed by Fisher's exact test or the $\chi^{2}$-test. Mann-Whitney and Kruskal-Wallis tests were used for non-parametric comparisons. The probability of overall and progression-free survival as a function of time was determined by the Kaplan-Meier method, and differences in survival curves were compared by the log-rank test. Multivariate survival analysis was performed using the Cox regression model. Generally, $P$-values $<0.05$ were regarded as significant. For the statistical analyses, SPSS software version 15.0 (SPSS Inc., Chicago, IL, USA) was applied.

\section{Results}

\section{Clinical and Pathological Characteristics of Patients with Ovarian Tumors}

Samples from 133 patients with invasive ovarian carcinomas were investigated for Top II $\alpha$ immunoreactivity. The distribution of clinicopathological parameters is shown in Table 1 . The mean (median) age of patients at surgery was 57.3 (57) years (range: $32-81)$. A total of $82(61.7 \%)$ specimens were serous carcinomas, 7 (5.2\%) were mucinous carcinomas, 17 $(12.9 \%)$ were endometroid carcinomas, $6(4.5 \%)$ were clear cell carcinomas, $7(5.2 \%)$ were transitional cell carcinomas and $14(10.5 \%)$ were undifferentiated carcinomas. For the statistical analysis, endometrioid, mucinous and transitional cell tumors were grouped into one group (nonserous tumors). Tumors were well differentiated in $22(16.5 \%)$ cases, moderately differentiated in 57 $(42.9 \%)$ cases and poorly differentiated in 54 $(40.6 \%)$ cases. The nuclear polymorphism was low in $21(15.8 \%)$ cases, medium in $69(51.9 \%)$ cases and high in $43(32.3 \%)$ cases. Overall survival data were available for all patients; $34(25.6 \%)$ patients had died during follow-up period. Overall survival time ranged from 2 to 83 months with a median (mean) survival time of 36 (35.9) months. Data on disease recurrence were available for 114 (86\%) patients. Progression-free survival was defined as the time between diagnosis and the first clinical or pathological evidence of local or distant disease recurrence. Progression-free survival ranged from 4 to 69 months with a median (mean) survival time of 24.0 (26.5) months.

\section{Top II $\alpha$ Immunostaining in Ovarian Tumors}

Nuclear immunoreactivity of Top II $\alpha$ was observed in $94.7 \%$ of ovarian carcinomas (126 out of 133), and was mostly of moderate-to-strong intensity. In most cases, an additional cytoplasmic staining was detected $(85.7 \%, 114$ out of 133 cases). Cytoplasmic staining was generally weaker than nuclear signals, and was diffusely distributed among different tumor areas. Stromal cells were negative for Top II $\alpha$ expression in most cases; however, in some tumors, a nuclear Top II $\alpha$ expression was observed in stromal fibroblasts. Different staining patterns of Top II $\alpha$ are shown in Figure 1a-d.

\section{Top II $\alpha$ mRNA Expression in Ovarian Carcinomas}

For the determination of mRNA expression, 100 cases were studied. Expression of Top II $\alpha$ mRNA was detectable in $76 \%$ of these specimens. The median normalized score was 5.8 (range: $0.1-8.9$ ); the 25th 
a
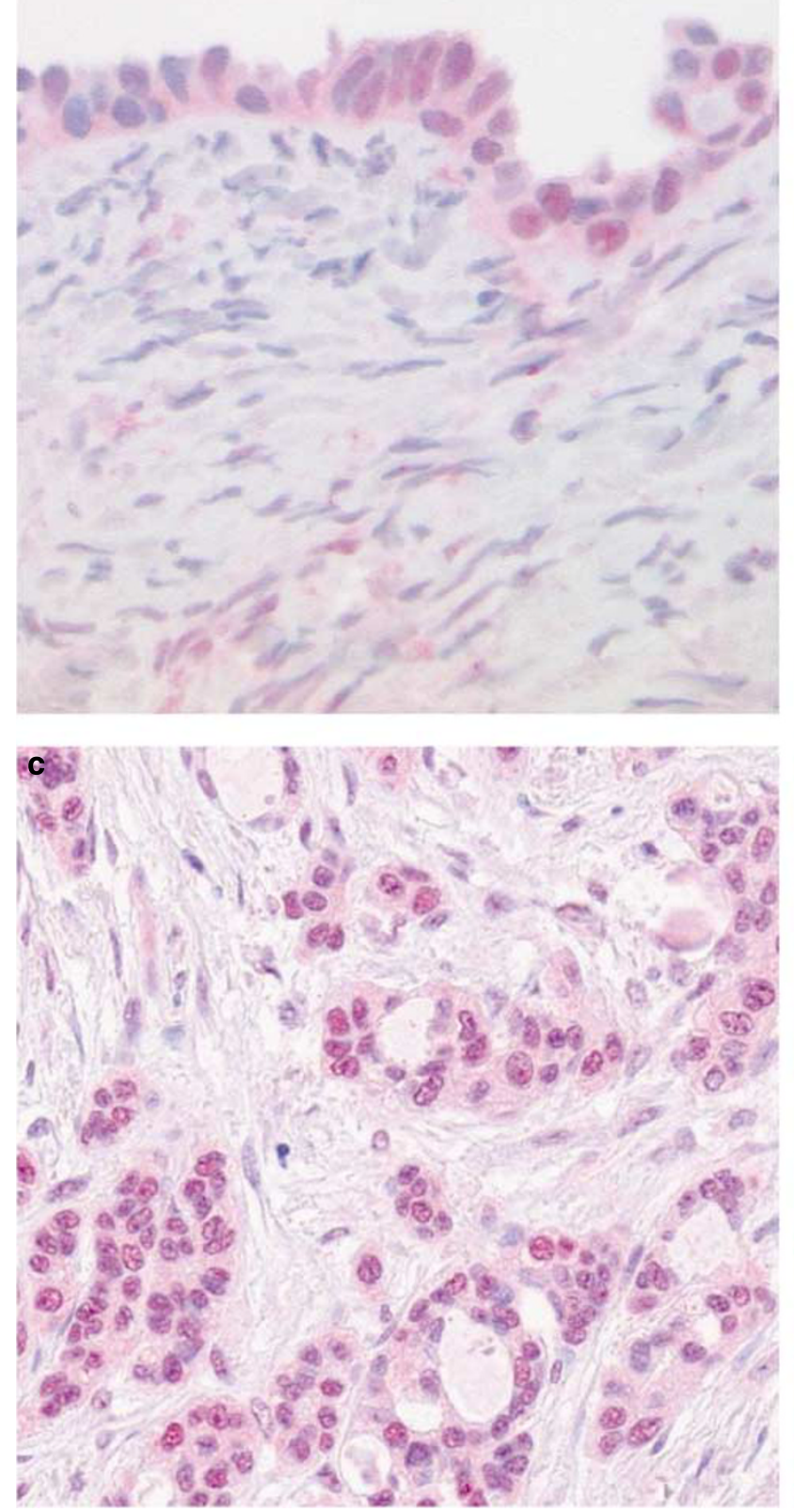
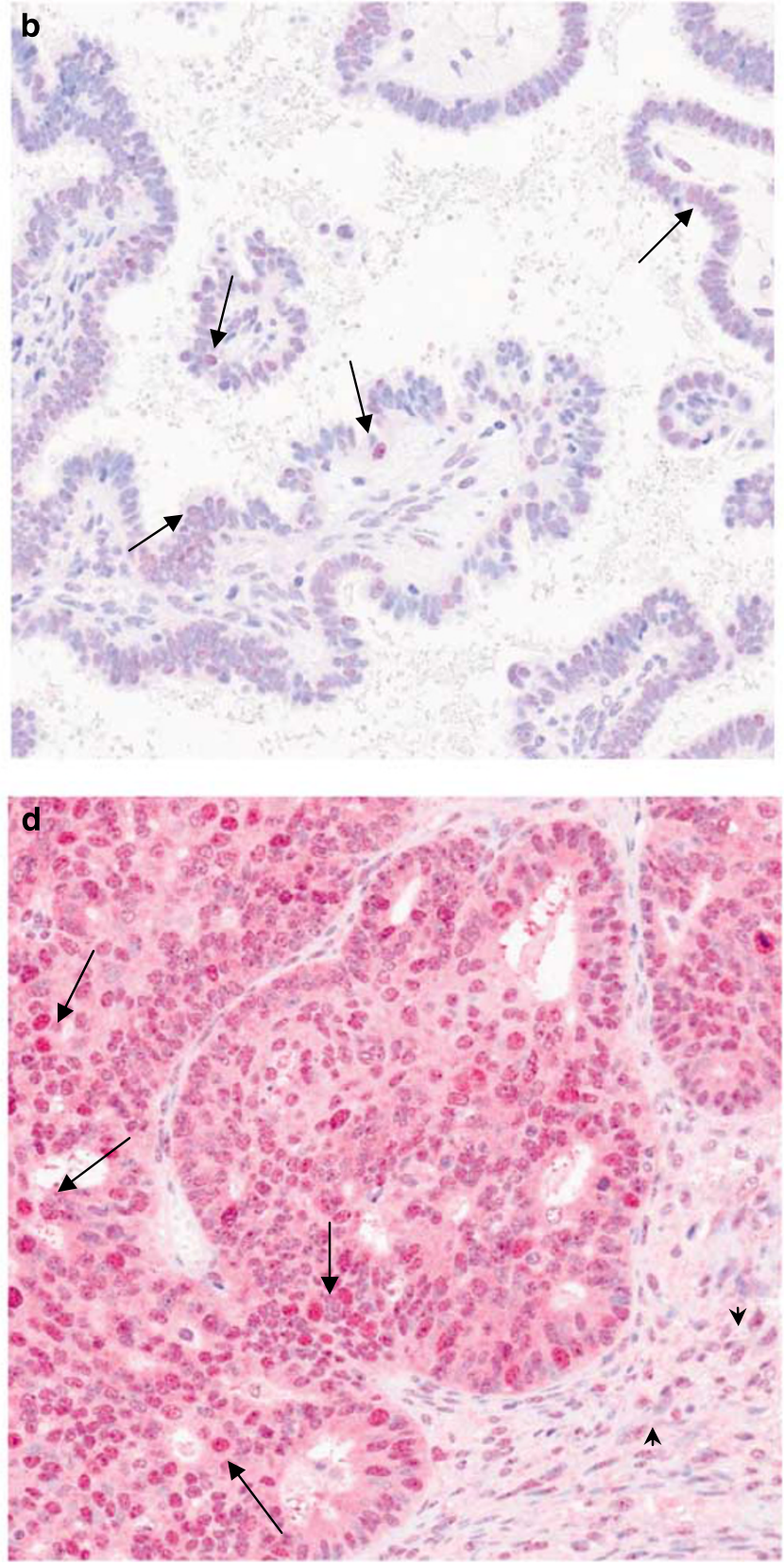

Figure 1 Immunohistochemistry. Expression of topoisomerase II $\alpha$ in ovarian tissues. (a) Weak nuclear staining of normal ovarian surface epithelium. (b) Very faint expression of Top II $\alpha$ in sparse nuclei of a highly differentiated serous ovarian carcinoma (arrows). (c) Invasive complexes of a moderately differentiated carcinoma reveal moderate nuclear and weak cytoplasmic Top II $\alpha$ expression. (d) A poorly differentiated ovarian serous carcinoma with moderate-to-strong expression of Top II $\alpha$ in the majority of the nuclei (arrows). The tumor cell cytoplasm is diffusely stained in moderate intensity (note the nuclear Top II $\alpha$ expression in stromal fibroblasts (arrowheads)).

and 75 th percentiles were 2.74 and 7.06 , respectively. There was no significant difference in Top II $\alpha$ mRNA expression between low and high Top II $\alpha$ protein-expressing tumors (data not shown).

\section{Association of Top II $\alpha$ Expression with Clinicopathological Features and CRM1 Expression}

Differences in Top II $\alpha$ expression (RNA and protein) between different groups of clinicopathological features were investigated by non-parametric tests (Figure 2). As shown in Figure 2a, high Top II $\alpha$ mRNA levels were significantly associated with higher tumor grade (G1 vs G2-3: $P=0.003$, MannWhitney test). Additionally, grades 2 and 3 tumors showed a trend toward higher levels of Top II $\alpha$ cytoplasmic protein expression (Figure 2b; $P=0.053$, Mann-Whitney test). As the Silverberg grading system used for the classification of ovarian carcinomas is on the basis of the three morphological parameters (nuclear polymorphism, mitotic rate 

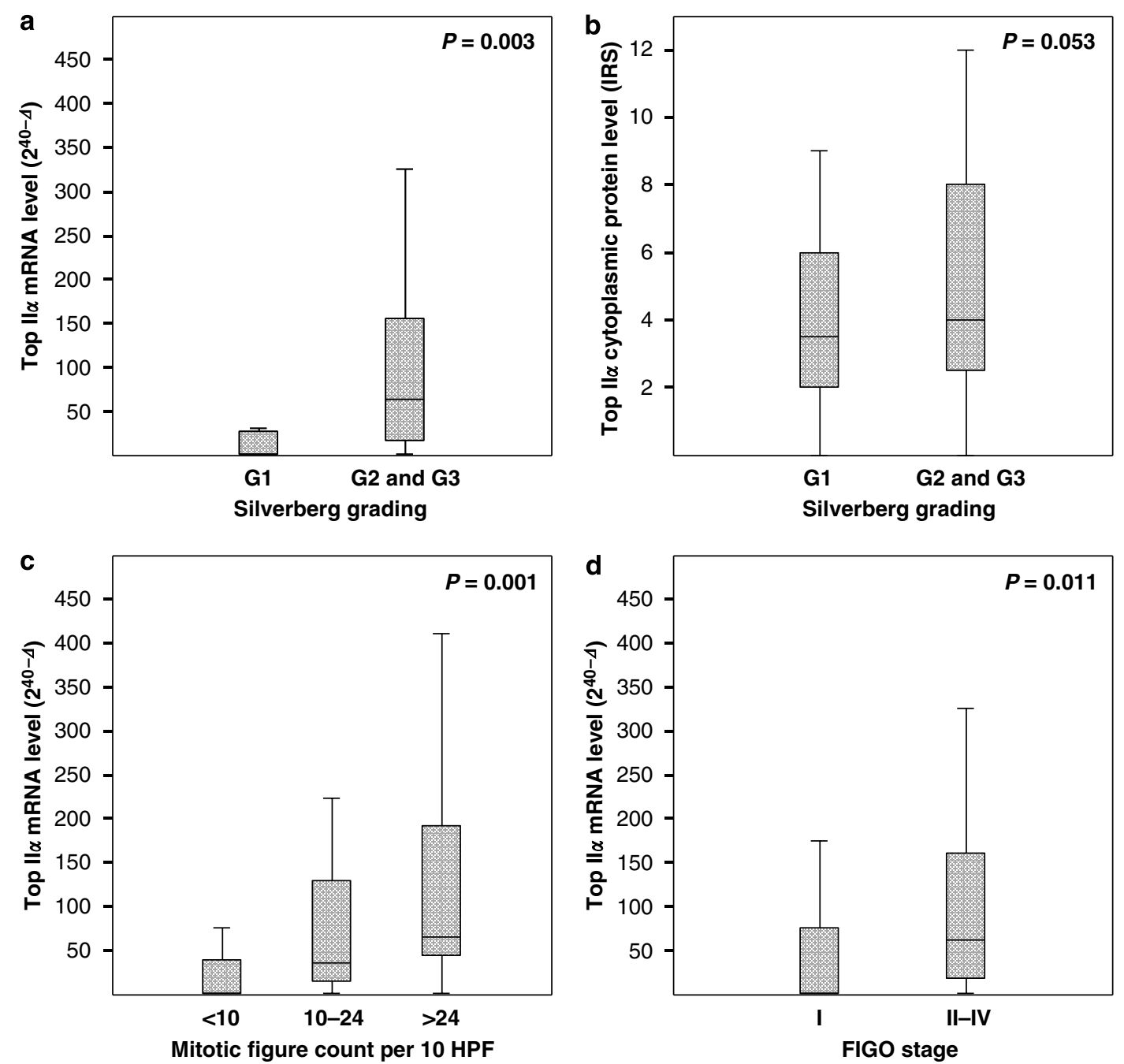

Figure 2 Correlation of topoisomerase II $\alpha$ expression with clinicopathological variables in ovarian carcinoma. (a) Top II $\alpha$ mRNA is significantly highly expressed in carcinomas of higher Silverberg grade ( $P=0.003$, Mann-Whitney test). (b) High Silverberg grade tumors show a trend toward higher cytoplasmic Top II $\alpha$ protein expression $(P=0.053$, Mann-Whitney test). (c) Top II $\alpha$ mRNA expression correlates significantly with mitotic rate (no of mitoses/10 high power field; $P=0.001$, Kruskal-Wallis test). (d) Top II $\alpha$ mRNA expression correlates significantly with FIGO stage $(P=0.011$, Mann-Whitney test).

and growth pattern), we evaluated the correlation between Top II $\alpha$ expression and each of these parameters independently. We observed a significant association between Top II $\alpha$ mRNA expression and mitotic rate (Figure 2c; $P=0.001$, KruskalWallis test), but there was no correlation with nuclear polymorphism or growth pattern. Advanced stage tumors (II-IV) had higher Top II $\alpha$ mRNA expression compared with stage I tumors (Figure 2d, $P=0.011$, Mann-Whitney test).

There was significant association between nodal stage $(\mathrm{pN})$, and each of nuclear and cytoplasmic protein expression $(P=0.030$ and $P=0.034$, respectively; Mann-Whitney test). mRNA expression correlated significantly with tumor stage (pT; $P=0.006$, Mann-Whitney test). No significant association was observed between RNA or protein expression and patient age or metastasis stage (pM).

In addition to the established clinicopathological parameters, we investigated the link between the expression of Top II $\alpha$ and CRM1. Cytoplasmic immunostaining of Top II $\alpha$ was significantly linked to CRM1 expression ( $P=0.008$, Figure 3$)$.

\section{Top II $\alpha$ Expression and Patient Survival}

Patients whose tumors revealed a high nuclear as well as cytoplasmic Top II $\alpha$ protein expression showed a shorter overall survival as well as progression-free survival compared to patients with tumors of low expression (Figure 4). In univariate survival analysis, nuclear protein expression of Top II $\alpha$ was found to be a significant prognostic factor for overall survival $(P=0.045)$, and cytoplasmic protein expression showed a borderline significance for overall survival $(P=0.056)$. A trend toward a reduced progression-free survival $(P=0.084)$ was seen in patients with high cytoplasmic expression of Top II $\alpha$ protein, whereas there was no significant correlation between nuclear 


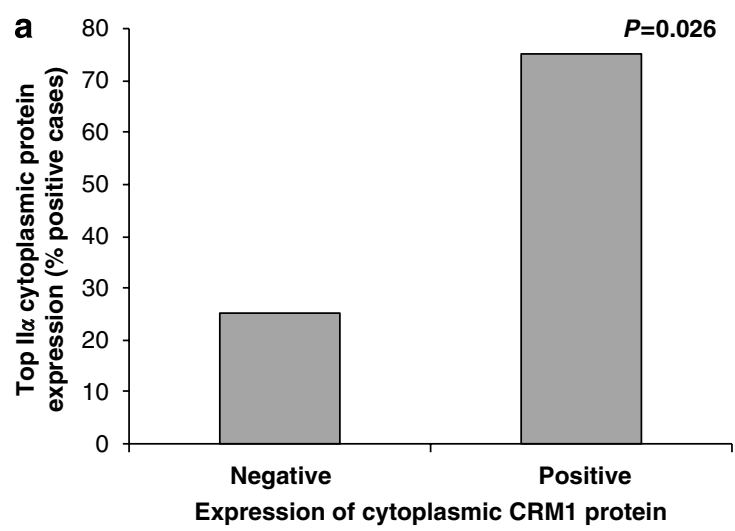

b
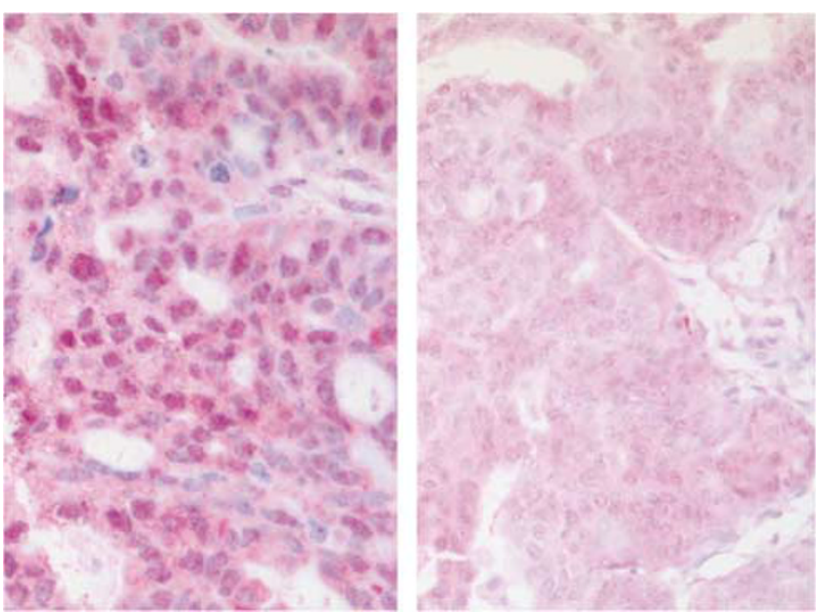

Figure 3 Association of protein expression of topoisomerase II $\alpha$ and CRM1 in ovarian carcinomas. (a) Association of cytoplasmic Top II $\alpha$ protein expression with CRM1 protein expression in ovarian carcinomas $(P=0.026$, Fisher's exact test). (b) Correspondence between cytoplasmic immunostaining of Top II $\alpha$ and CRM1 in the same tumor specimen stained for Top II $\alpha$ (left) and for CRM1 (right).

expression of Top II $\alpha$ protein and progression-free survival. mRNA expression of Top II $\alpha$ had no significant association with neither overall nor progression-free survival (Figure 4).

The known prognostic factors in ovarian carcinoma, such as lymph node stage, histological grade, and age at diagnosis, in addition to intraoperative residual tumor were prognostic factors for overall survival in our study group, as well (Table 2). For progression-free survival, FIGO stage, histological type, tumor stage, lymph node stage, tumor grade and residual tumor were significant prognostic factors (data not shown).

\section{Discussion}

In this study, we investigated the expression of topoisomerase $\mathrm{II} \alpha$ in primary invasive ovarian carcinomas at the protein and mRNA levels. Our results show an increased expression of Top II $\alpha$ in higher grade and advanced stage tumors as well as a
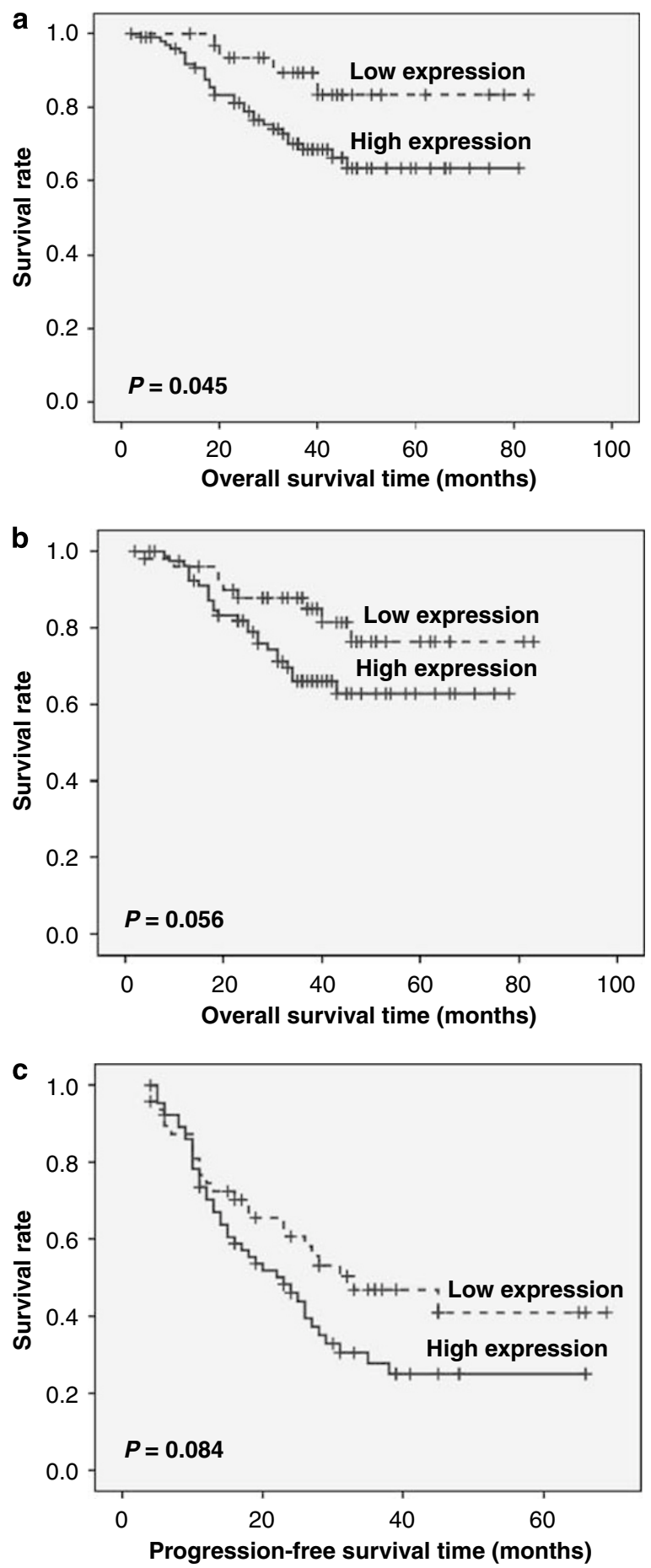

Figure 4 Univariate survival analysis according to nuclear or cytoplasmic protein expression of topoisomerase $\mathrm{II} \alpha$ in patients with ovarian cancer. Nuclear Top II $\alpha$ expression is a prognostic factor for overall survival (a; $P=0.045$, log-rank test). A trend toward a reduced overall $(\mathbf{b} ; P=0.056)$ as well as progression-free survival (c; $P=0.084)$ in patients whose tumors express Top II $\alpha$ in the cytoplasm is evident. Solid lines: cases with high expression; dotted lines: cases with low expression; + : censored.

correlation of high expression with worse survival. Furthermore, to the best of our knowledge, for the first time, we report a link between cytoplasmic 
Table 2 Univariate survival analysis (Kaplan-Meier)

\begin{tabular}{|c|c|c|c|c|}
\hline \multirow[b]{2}{*}{ Characteristic } & \multicolumn{4}{|c|}{ Overall survival } \\
\hline & Cases (n) & Events (n) & $\begin{array}{l}\text { Mean survival time } \\
\quad \text { (months } \pm \text { s.e.) }\end{array}$ & Log-rank test \\
\hline Nuclear Top II $\alpha$ protein expression & & & & 0.045 \\
\hline Low & 32 & 4 & $74.2 \pm 4.1$ & \\
\hline High & 101 & 30 & $60.3 \pm 3.1$ & \\
\hline Cytoplasmic Top II $\alpha$ protein expression & & & & 0.056 \\
\hline Low & 51 & 9 & $70.1 \pm 3.9$ & \\
\hline High & 82 & 25 & $57.9 \pm 3.3$ & \\
\hline Top II $\alpha$ mRNA expression $(n=100)$ & & & & 0.241 \\
\hline Low & 50 & 15 & $61.2 \pm 4.6$ & \\
\hline High & 50 & 11 & $65.4 \pm 4.3$ & \\
\hline FIGO stage & & & & 0.050 \\
\hline I & 26 & 3 & $74.1 \pm 3.7$ & \\
\hline II-IV & 107 & 31 & $61.8 \pm 3.2$ & \\
\hline Histological grade (Silverberg) & & & & 0.023 \\
\hline G1 & 22 & 3 & $73.7 \pm 5.0$ & \\
\hline G2 & 57 & 11 & $62.0 \pm 3.5$ & \\
\hline G3 & 54 & 20 & $52.4 \pm 3.9$ & \\
\hline Age at surgery (years) & & & & 0.008 \\
\hline$\leq 60$ & 77 & 14 & $70.7 \pm 2.9$ & \\
\hline$>60$ & 56 & 20 & $55.2 \pm 4.6$ & \\
\hline Intraoperative residual tumor & & & & 0.000 \\
\hline Residual tumor $\leq 2 \mathrm{~cm}$ & 81 & 16 & $68.4 \pm 3.2$ & \\
\hline Residual tumor $>2 \mathrm{~cm}$ & 12 & 7 & $30.4 \pm 5.1$ & \\
\hline
\end{tabular}

FIGO, International Federation of Gynecology and Obstetrics.

Mean overall survival time of all patients according to the clinicopathological data and topoisomerase II $\alpha$ expression.

expression of Top II $\alpha$ and CRM1 in human ovarian tumors.

We have undertaken an approach that facilitates the evaluation of both mRNA and protein expression from the same routinely processed FFPE tissue blocks used in pathology laboratories for diagnostic purposes. We were thus able to evaluate gene expression in a large clinicopathologically characterized ovarian cancer cohort at the transcriptional and translational levels retrospectively without the requirement of special processing or preservation of specimens, as opposed to earlier studies on Top II $\alpha$ in ovarian cancer surgical specimens, which required frozen tissue samples for the determination of Top II $\alpha$ protein and RNA expression. ${ }^{13,14,26-28} \mathrm{We}$ employed a new technique for RNA extraction from FFPE tissues, which is based on magnetic beads separation of nucleic acids, and used the sensitive real-time qRT-PCR method with specific TaqMan primer/probe to assess the transcriptional level of the Top II $\alpha$ gene. Using this new technique, we showed that the determination of mRNA expression helps to identify aggressive tumors (high grade and high stage), and was linked to the mitotic activity of the tumor cells, yet does not add prognostic information compared with the evaluation of Top II $\alpha$ protein expression. Interestingly, mRNA expres- sion was not related to the protein expression levels, which could point to a post-translational regulation of the Top II $\alpha$. This post-translational regulation might be related to the interesting staining patterns (nuclear and cytoplasmic), which also suggest that other proteins might interact with Top II $\alpha$ protein and modify its cellular localization and function.

An interesting finding of our study was the detection of a distinct cytoplasmic localization of Top II $\alpha$ in a subset of tumors. Several cell culture experiments have pointed out to a correlation of cytoplasmic trafficking of Top II $\alpha$ with acquired drug resistance to Top II poisons in cell lines under drug selection, or in patient samples obtained after exposure to chemotherapy. ${ }^{29,30}$

Recently, de Lucio et $a l^{31}$ has characterized a human lung cancer cell line with an intrinsic resistance to etoposide that was mediated by cytoplasmic localization of topoisomerase II $\alpha$. Cytoplasmic Top II $\alpha$ expression was further found to be associated with increased resistance, and hence poor survival in leukemia in children treated with a regimen containing a Top II poison. ${ }^{32}$ Resistance to Top II inhibitors could thus be due to an ectopic cytoplasmic localization of Top II $\alpha$, leading to the decreased formation of enzyme/DNA complexes in the nucleus, which could be targeted by the Top II $\alpha$ 
inhibitors, and by this mechanism reducing the sensitivity of the cell to the drug.

Interestingly, in our study, we observed cytoplasmic expression of Top II $\alpha$ in samples from patients who have not received any chemotherapy before collection of tumor specimens.

We found a significant correlation between Top II $\alpha$ and CRM1 cytoplasmic proteins. In earlier cell culture studies, it was reported that nuclear export of Top II $\alpha$ is mediated by CRM1, a mechanism, which could be blocked by the CRM1 inhibitor lepotomycin B (LMB). ${ }^{33-35}$ Our data reveal an in vivo implication of nuclear export mechanisms in Top II $\alpha$ cytoplasmic localization.

We observed that Top II $\alpha$ expression has a significant association with stage; this finding is similar to the results reported by van der Zee et al. ${ }^{26}$ The finding of an association of increased expression of Top II $\alpha$ with poor differentiation is in line with the findings in ovarian cancer, ${ }^{26}$ and in prostate tumors. ${ }^{15,16}$

Similar to our finding of a significant inverse correlation of Top II $\alpha$ expression and survival, other groups have detected an unfavorable prognostic impact of Top II $\alpha$ expression in ovarian cancer as well as in other series of neoplasms, such as breast cancer, synovial sarcoma, lung cancer and endometrial carcinoma. ${ }^{20,36-40}$ One explanation for the shorter survival rate associated with elevated Top II $\alpha$ levels could be an enhancement of tumor cell proliferation, which results in an increased tumor aggressiveness. ${ }^{6,7,41}$ On the other hand, high Top II $\alpha$ expression might indicate tumor sensitivity to Top II $\alpha$ inhibitors, as it reflects target availability. Several authors had shown a direct correlation between the sensitivity of a cell to Top II $\alpha$ targeting drugs and the level of Top II $\alpha,{ }^{42-44}$ and in vitro chemosensitivity testing of ovarian carcinoma specimens has provided evidence that the Top II $\alpha$ expression could reflect chemosensitivity to Top II-targeting drugs. ${ }^{45}$ Top II $\alpha$ expression could thus be used as a predictor of response to chemotherapy. Patients with increased Top II $\alpha$ expression might benefit more from chemotherapeutic protocols involving Top II-targeted drugs; hence their outcome could be improved. Our finding is in accordance with other studies in ovarian cancer patients treated with platinum-based regimens. ${ }^{13,40}$ Yet, due to its role as a marker for an active cell cycle, Top II $\alpha$ expression might be an indicator for chemoresponse in general as the latter is strongly dependent on proliferation.

In conclusion, Top II $\alpha$ expression showed prognostic importance as shorter survival was associated with increased Top II $\alpha$ expression. On the basis of our results, we suggest Top $\mathrm{II} \alpha$ as a candidate prognostic factor for ovarian cancer, which should be evaluated in large-scale clinical trials. The determination of the immunoreactive pattern of Top II $\alpha$ expression, together with other clinicopathological factors, might help to identify high-risk patients, and to plan an individualized therapy. In the future, it would further be interesting to characterize the potential role of Top II $\alpha$ as a predictor of tumor response to chemotherapy in prospective studies on ovarian cancer patients, including samples obtained pre- and post-chemotherapeutic treatment, especially with Top II $\alpha$ inhibiotors, such as pegylated doxorubicin and etoposide.

\section{Acknowledgements}

We thank Mrs Ines Koch for the expert technical assistance and Mrs Martina Eickmann for editorial assistance. AF was supported by DAAD (Deutscher Akademischer Austauschdienst), Germany and the University of Gezira, Sudan.

\section{References}

1 Jemal A, Siegel R, Ward E, et al. Cancer Statistics, 2008. CA Cancer J Clin 2008;58:71-96.

2 Ozols RF, Bookman MA, Connolly DC, et al. Focus on epithelial ovarian cancer. Cancer Cell 2004;5:19-24.

3 Wang JC. Cellular roles of DNA topoisomerases: a molecular perspective. Nat Rev Mol Cell Bio 2002; $3: 430-440$.

4 Nitiss JL. Investigating the biological functions of DNA topoisomerases in eukaryotic cells. Biochim Biophys Acta 1998;1400:63-81.

5 Champoux JJ. DNA topoisomerases: structure, function, and mechanism. Annu Rev Biochem 2001;70: $369-413$.

6 Turley H, Comley M, Houlbrook S, et al. The distribution of the two isoforms of DNA topoisomerase II in normal and neoplastic human tissues. Br J Cancer 1997;75:1340-1346.

7 Heck MM, Earnshaw WC. Topoisomerase II: A specific marker for cell proliferation. J Cell Biol 1986;103: 2569-2581.

8 Hsiang YH, Wu HY, Liu LF. Proliferation-dependent regulation of DNA topoisomerase II in cultured human cells. Cancer Res 1988;48:3230-3235.

9 Burden DA, Osheroff N. Mechanism of action of eukaryotic topoisomerase II and drugs targeted to the enzyme. Biochim Biophys Acta 1998;1400:139-154.

10 Liu LF. DNA topoisomerase poisons as antitumor drugs. Annu Rev Biochem 1989;58:351-375.

11 Nitiss JL, Wang JC. Mechanisms of cell killing by drugs that trap covalent complexes between DNA topoisomerases and DNA. Mol Pharmacol 1996;50:1095-1102.

12 D'Arpa P, Liu LF. Topoisomerase targeting antitumor drugs. Biochem Biophys Acta 1989;989:163-177.

13 Cornarotti M, Caparinco G, Bohm S, et al. Gene expression of DNA topoisomerase I, II alpha and beta and response to cisplatin-based chemotherapy in advanced ovarian carcinoma. Int J Cancer 1996; 67:479-484.

14 Naniwa J, Kigwa J, Kanamori Y, et al. Genetic diagnosis for chemosensitivity with drug- resistance genes in epithelial ovarian cancer. Int J Gynecol Cancer 2007;17:76-82.

15 Hughes C, Murphy A, Martin C, et al. Topoisomerse II alpha increases with increasing Gleason score and 
with hormone insensitivity in prostate carcinoma. J Clin Pathol 2006;59:721-724.

16 Willman JH, Holden JA. Immunohistochemical staining for DNA topoisomerase II alpha in benign, premalignant, and malignant leisions of the prostate. Prostate 2000;42:280-286.

17 Brown MS, Holden JA, Rahn MP, et al. Immunohistochemical staining for DNA topoisomerase II $\alpha$ in Hodgkin's disease. Am J Clin Pathol 1998;109:39-44.

18 Iino K, Sasano H, Yabuki N, et al. DNA topoisomerase II alpha and Ki-67 in human adrenocortical neoplasms: a possible marker of differentiation between adenomas and carcinomas. Mod Pathol 1997;10:901-907.

19 Giaccone G, van Ark-otte J, Scagliotti G, et al. Differential expression of DNA topoisomerase in nonsmall cell lung cancer and normal lung. Biochim Biophys Acta 1995;1264:337-346.

20 Depowski PL, Rosenthal SI, Brien TP, et al. Topoisomerase II $\alpha$ expression in breast cancer: correlation with outcome variables. Mod Pathol 2000;13:542-547.

21 Godfrey TE, Kim S-H, Marielena C, et al. Quantitative mRNA expression analysis from formalin-fixed, paraffin-embedded tissues using $5^{\prime}$ nuclease quantitative reverse transcription-polymerase chain reaction. J Mol Diagn 2000;2:84-91.

22 Lehmann U, Kreipe H. Real-time PCR analysis of DNA and RNA extracted from formalin-fixed and paraffinembedded biopsies. Methods 2001;25:409-418.

23 Kudo N, Khochbin S, Nishi K, et al. Molecular cloning and cell-cycle dependent expression of mammalian CRM1, a protein involved in nuclear export of proteins. J Biol Chem 1997;272:29742-29751.

24 Shimizu Y, Kamoi S, Amada S, et al. Toward the development of a universal grading system for ovarian epithelial carcinoma. Gynecol Oncol 1998;70:2-12.

25 Noske A, Weichert W, Niesporek S, et al. Expression of the nuclear export protein chromosomal region maintenance/exportin 1/Xpo1 is a prognostic factor in human ovarian cancer. Cancer 2008;112:733-743.

26 van der Zee AGJ, De Vries EGE, Hollema $\mathrm{H}$, et al. Molecular analysis of the topoisomerase II $\alpha$ gene and its expression in human ovarian cancer. Ann Oncol 1994;5:75-81.

27 Withoff S, van der Zee AG, de Jong S, et al. DNA topoisomerase $\alpha$ and $\beta$ expression in human ovarian cancer. Br J Cancer 1999;79:748-753.

28 Chekerov R, Klaman I, Zafrakas M, et al. Altered expression of topoisomerase $\mathrm{II} \alpha$ in ovarian tumor epithelial and stromal cells after platinum- based chemotherapy. Neoplasia 2006;8:38-45.

29 Valkov NI, Gump JL, Engel R, et al. Cell densitydependant VP-16 sensitivity of leukemic cells is accompanied by the translocation of topoisomerase II-alpha from the nucleus to the cytoplasm. Br J Haematol 2000;108:331-345.

30 Engel R, Valkov NI, Gump JL, et al. The cytoplasmic trafficking of DNA topoisomerase II-alpha correlates with etoposide resistance in human myeloma cells. Exp Cell Res 2004;295:421-431.
31 De Lucio B, Manuel V, Barrera-Rodriguez R. Characterization of human NSCLC cell line with innate etoposide- resistance mediated by cytoplasmic localization of topoisomerase II alpha. Cancer Sci 2005;96:774-783.

32 Grandgirard N, Ly-Sunnarm B, Ferrat D, et al. Impact of topoisomerase II alpha on the clinical outcome of children with acute lymphoblastic leukemia. Leuk Res 2004;28:479-486.

33 Mirski SE, Bielawski JC, Cole SP. Identification of functional nuclear export sequence in human topoisomerase II alpha and beta. Biochem Biophys Res Commun 2003;306:905-911.

34 Turner JG, Engel R. Human topoisomerase II $\alpha$ nuclear export is mediated by two CRM-1-dependent nuclear export signals. J Cell Sci 2004;117:3061-3071.

35 Kudo N, Wolff B, Sekimoto T, et al. Leptomycin B inhibition of signal-mediated nuclear export by direct binding to CRM1. Exp Cell Res 1998;242:540-547.

36 O’Connor JK, Hazard LJ, Avent JM, et al. Topoisomerase II $\alpha$ expression correlates with diminished diseasefree survival in invasive breast cancer. Int J Radiat Oncol Biol Phys 2006;65:1411-1415.

37 Oda Y, Ohishi Y, Saito T, et al. Nuclear expression of Ybox- binding protein-1 correlates with P-glycoprotein and topoisomerase II $\alpha$ expression, and with poor prognosis in synovial sarcoma. J Pathol 2003;199: 251-258.

38 Dingemans AC, van Ark-Otte J, Span S, et al. Topoisomerase II $\alpha$ and other drug resistance markers in advanced non-small cell lung cancer. Lung cancer 2001;32:117-128.

39 Costa MJ, Hansen CL, Holden JA, et al. Topoisomerase II $\alpha$ : prognostic predictor and cell cycle marker in surface epithelial neoplasms of the ovary and peritoneum. Int J Gynecol Pathol 2000;9:248-257.

40 Bildrici K, Tel N, Ozalp SS, et al. Prognostic significance of DNA topoisomerase II- alpha (Ki-S1) immunoexpression in endometrial carcinoma. Eur J Gynaecol Oncol 2002;23:540-544.

41 Lynch BJ, Guinee DG, Holden JA. Human DNA topoisomerase II-alpha: a new marker of cell proliferation in invasive breast cancer. Hum Pathol 1997;28: 180-188.

42 Davies SM, Robson CN, Davies SL, et al. Nuclear topoisomerase II levels correlate with the sensitivity of mammalian cells to intercalating agents and epipodophyllotoxins. J Biol Chem 1988;263:17724-17729.

43 Fry AM, Chresta CM, Davies SM, et al. Relationship between topoisomerase II level and chemosensitivity in human tumor cell lines. Cancer Res 1991;51: 6592-6595.

44 Potmesil M, Hsiang YH, Liu LF, et al. Resistance of human leukemic and normal lymphocytes to druginduced DNA cleavage and low levels of DNA topoisomerase II. Cancer Res 1988;48:3537-3543.

45 Koshiyama M, Fujii H, Kinezaki M, et al. Correlation between Topo II $\alpha$ expression and chemosensitivity testing for Topo II targeting drugs in gynaecological carcinomas. Anticancer Res 2001;21:905-910. 